\title{
Ependimom ve L-2-hidroksiglutarik asidüri: İki kardeş olgu sunumu
}

\section{Ependymoma with L-2-hydroxyglutaric aciduria: case report of two siblings}

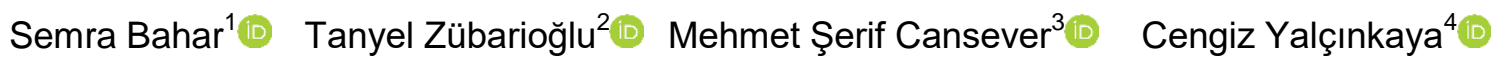 \\ ${ }^{1}$ Sağlık Bilimleri Üniversitesi, Şişli Hamidiye Etfal Eğitim ve Araştırma Hastanesi, Çocuk Sağlığı ve \\ Hastalıkları Kliniği, İstanbul, Türkiye \\ ${ }^{2}$ Sağıı Bilimleri Üniversitesi, Şişli Hamidiye Etfal Eğitim ve Araştırma Hastanesi, Çocuk Sağlığı ve \\ Hastalıkları Kliniği, Çocuk Beslenme ve Metabolizma Bölümü, İstanbul, Türkiye \\ ${ }^{3}$ Namık Kemal Üniversitesi, Sağlık Hizmetleri Meslek Yüksekokulu, Tıbbi Laboratuvar Teknikleri, \\ Tekirdağ, Türkiye \\ ${ }^{4}$ İstanbul Üniversitesi, Cerrahpaşa Tıp Fakültesi, Nöroloji Anabilim Dalı, İstanbul, Türkiye
}

\section{Öz}

L-2-hidroksiglutarik asidüri (L2HGA), yavaş seyirli, otozomal çekinik geçişli, nörodejeneratif bir metabolik hastalıktır. Hastalığın temel klinik bulgularını motor gelişim basamaklarında gecikme, davranış bozuklukları, febril ve afebril nöbetler oluşturup, sık görülen muayene bulguları arasında makrosefali, mental retardasyon, serebellar ataksi, piramidal ve ekstrapiramidal bulgular yer alır. Beyin manyetik rezonans görüntülemesinde (MRG) subkortikal alandan başlayan beyaz cevher etkilenmesi ile bazal gangliyon ve serebellar dentat nükleus tutulumu tipiktir. Kesin tanı klinik ve radyolojik görüntülemelerin eşliğinde serumda, idrarda ve beyin omurilik sıvısında (BOS) artmış 2-hidroksiglutarik asit düzeyinin gösterilmesi ve $\mathrm{L} 2 \mathrm{HGDH}$ geninin moleküler analizi ile konulur. L2HGA tanısıyla takip edilen hastalarda beyin neoplazmı gelişimi bildirilmiştir. Bu yazıda, adolesan dönemde beyin tümörü nedeniyle opere edilen bir hastada patolojik beyin MRG bulgularının varlığının L2HGA tanısı koydurduğu bir hasta sunulmuştur. Tanı sonrası yapılan aile taramasında hastanın kardeşi de L2HGA tanısı almıştır. Sunulan olguların ışığında, erken yaşta beyin tümörü saptanan hastalarda, eşlik eden gelişim basamaklarında gecikme, mental retardasyon ve patolojik muayene bulgularının varlığında metabolik hastalıkların da ayırıcı tanıda akılda tutulması, nöro-metabolik hastalıkların spesifik radyolojik bulgularının üzerinde durulması ve metabolik hastalıklarda aile taramasının önemi vurgulanmıştır.

Anahtar Sözcükler: L-2-hidroksiglutarik asidüri, neoplazm, manyetik rezonans görüntülemesi.

\begin{abstract}
L-2-hydroxyglutaric aciduria (L2HGA) is a slowly progressive, autosomal recessive neurodegenerative disorder. Characteristic clinical features of the disease include developmental delay, behavioral disorders, febrile and afebrile seizures. Frequent abnormal examination findings can be listed as macrocephaly, mental retardation, cerebellar ataxia, pyramidal and extrapyramidal signs. Brain magnetic resonance imaging (MRI) features are characterized by subcortical white matter, basal ganglia and cerebellar dentate nuclei alterations. Definite diagnosis can be made by determination of elevated 2-hydroxyglutaric acid accumulation in plasma, urine and cerebrospinal fluid and by molecular diagnosis of L2HGDH gene accompanied by clinical and radiological findings. Malignant brain tumors have been reported in the course of L2HGA. Here, a patient that was operated because of brain tumor in adolescence and in whom the L2HGA diagnosis was made by abnormal brain MRI features is reported.
\end{abstract}

\footnotetext{
Yazışma Adresi: Semra Bahar

Sağlık Bilimleri Üniversitesi, Şişli Hamidiye Etfal Eğitim ve

Araştırma Hastanesi, Çocuk Sağlığı ve Hastalıkları Kliniği,

İstanbul, Türkiye

E-mail: semraabahar@gmail.com

Makalenin Geliş Tarihi: 09.10.2018 
Following the diagnosis, her sister was also diagnosed as L2HGA due to family screening. In the light of these cases, it is emphasized that metabolic diseases should be included in differential diagnosis of brain tumors in early life especially in existence of neurodevelopmental delay, mental retardation and pathological examination findings. Specific radiological features of neurometabolic disorders and importance of family screening in metabolic diseases are also highlighted.

Keywords: L-2-hydroxyglutaric aciduria, neoplasm, magnetic resonance imaging.

\section{Giriş}

L-2-hidroksiglutarik asidüri (L2HGA), ilk kez 1980 yılında tanımlanan yavaş seyirli, otozomal çekinik geçişli nörodejeneratif bir metabolik hastalıktır. Hastalıktan L2HGDH genindeki homozigot ve/veya birleşik heterozigot mutasyonlara ikincil gelişen L2-hidroksiglutarat dehidrogenaz enzim aktivitesindeki azalma sorumludur (1). Hastalığın temel klinik bulgularını, motor gelişim basamaklarında gecikme, davranış bozuklukları, febril ve afebril nöbetler oluşturup, sık görülen muayene bulguları arasında makrosefali, mental retardasyon, serebellar ataksi, piramidal ve ekstrapiramidal bulgular yer alır (2). Beyin manyetik rezonans görüntülemesinde (MRG) subkortikal alandan başlayan beyaz cevher etkilenmesi ile bazal gangliyon ve serebellar dentat nükleus tutulumu tipiktir (3). Kesin tanı klinik ve radyolojik görüntülemelerin eşliğinde serumda, idrarda ve beyin omurilik sıvısında (BOS) artmış 2hidroksiglutarik asit düzeyinin gösterilmesi ve L2HGDH geninin moleküler analizi ile konulur (2). Hastalığın spesifik tedavisi olmamakla beraber Lkarnitin, riboflavin, flavin adenin dinükleotid sodyum ve düşük proteinli diyet kullanan hastalar mevcuttur. Az sayıda hastada klinik iyilik hali sağlanmıştır $(4,5)$. L2HGA tanısıyla takip edilen hastalarda yaşamın ilerleyen dönemlerinde medulloblastom, primitif nöroektodermal tümör ve fibriler astrositom gibi beyin neoplazmları gelişebildiği bildirilmiştir (2). Bu yazıda, erken yaşta beyin tümörü nedeniyle opere edilen bir hastada patolojik beyin MRG bulgularının varlığının L2HGA tanısı koydurduğu bir hasta sunulmuştur. Tanı sonrası yapılan aile taramasında hastanın kardeşi de L2HGA tanısı almıştır. Hastaların yasal vasisinden tıbbi verilerinin yayınlanabileceğine ilişkin yazılı onam belgesi alınmıştır.

\section{Olgu Sunumu}

\section{Olgu 1}

17 yaş 5 aylık kız hasta mental retardasyon nedeniyle yapılan takiplerinde çekilen beyin MRG'sinde, beyin tümörü saptandığı için opere edildikten sonra, ak madde değişikliklerinin de olması nedeniyle tarafımıza yönlendirildi. Hikâyesinde nöro-gelişimsel basamakları gecikmeli olarak kazandığı, ilk defa bir yaşında afebril nöbet geçirdiği, nöbetlerinin tekli antiepileptik tedavi ile kontrol altında olduğu öğrenildi. Özel eğitim alıyordu. Anne ve babası arasında birinci derece kuzen evliliği vardı. Ailenin altıncı çocuğu olarak dünyaya gelen hastanın 14 yaşındaki kız kardeşinde de mental retardasyon mevcuttu. Amcası beyin tümörü nedeni ile ölmüştü. Nörolojik muayenesinde; komutları algılamada güçlüğü olan hastanın ataksisi vardı, tandem yürüyüş testi bozuktu.

Biyokimyasal tetkiklerinde; tam kan sayımı, karaciğer enzimleri, kas enzimleri, böbrek fonksiyon testleri ve elektrolitleri normaldi. Plazma amonyak, kan gazı, laktat düzeyleri normal saptandı. Metabolik tetkikleri alınan hastanın Tandem kütle spektrometrisi ile yapılan asilkarnitin profili analizi ve kan aminoasitleri normaldi. Bakılan idrar organik asit analizinde 2-hidroksiglutarik asit atılımında belirgin artış $(403,5 \mathrm{mmol} / \mathrm{mol}$ kreatinin; $\mathrm{N}:<35)$ saptandı. Operasyon öncesinde çekilen MRG'sinde sağ hemisferde temporo-parietal bölgede, kistik komponenti olan, heterojen kontrast tutan, çevre dokulara bası yapan kitlesi mevcuttu. T2 kesitlerinde, beynin tüm loblarında subkortikal alandan başlayan diffüz tutulum olduğu görüldü (Şekil-1a-b). Beyin tümörü patolojisi evre 3 anaplastik ependimom ile uyumlu olan hastanın L2HGDH geni moleküler analizinde p.Gly55Asp (c.164 G>A) homozigot mutasyonu saptandı.

\section{Olgu 2}

14 yaş 7 aylık kız hasta; kardeşine L2HGA tanısı konulması üzerine aile taraması amacıyla polikliniğimize getirildi. Dört yaşından itibaren dengesiz yürüme, okula başladıktan sonra kalem tutmada zorluk, el becerilerinde azalma ve arkadaş ilişkilerinde bozulma yakınmalarının olduğu öğrenildi. Nörolojik muayenesinde; komutları algılamada güçlüğü olduğu görülen hastanın derin tendon refleksleri bilateral artmıştı, serebellar 
testlerde ardışık hareketlerde beceriksizlik ve intansiyonel tremoru mevcuttu. Tandem yürüme testi bozuktu. İdrar organik asit analizinde 2hidroksiglutarik asit atılımında belirgin artış $(411,6$ $\mathrm{mmol} / \mathrm{mol}$ kreatini; $\mathrm{N}:<35$ ) saptanan hastanın MRG'sinde bilateral serebellar dentat nükleus tutulumu ile simetrik, yaygın subkortikal ak madde ve korpus striatum tutulumu mevcuttu. Periventriküler ak madde korunmuştu (Şekil-1c-e). L2HGDH geni moleküler analizinde p.Gly55Asp (c.164 G>A) homozigot mutasyonu saptandı.

L2HGA tanısı konulan hastalara L-karnitin 100 $\mathrm{mg} / \mathrm{kg} / \mathrm{gün}$, koenzim $100 \mathrm{mg} / \mathrm{gün}$ ve riboflavin 100 $\mathrm{mg} / \mathrm{gün}$ tedavileri başlandı.

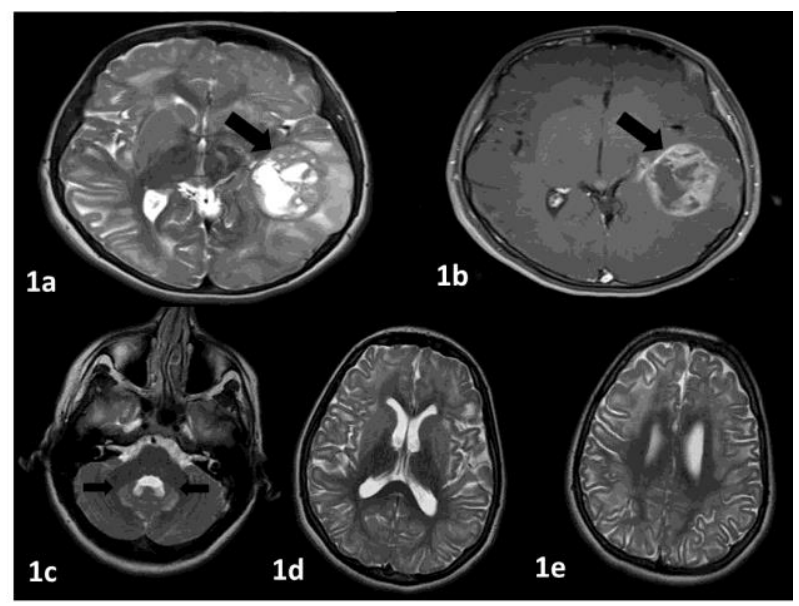

Şekil-1. Hastalara ait beyin manyetik rezonans görüntülemeleri (1a, 1b) Olgu1'de Aksiyal T2 ağırlıklı kesitte sağ hemisferde temporo-parietal bölgede, kistik komponenti olan, heterojen kontrast tutan, çevre dokulara bası yapan kitle ve ayrıca bilateral yaygın subkortikal ak madde tutulumu (1c-1e) Olgu2'de sırasıyla Aksiyal T2 ağırlıklı kesitte bilateral dentat nükleus tutulumu, bilateral, simetrik, yaygın subkortikal ak madde ve korpus striatum tutulumu, korunmuş periventriküler ak madde görülmektedir.

\section{Tartışma}

L-2-hidroksiglutarik asidüri nörodejeneratif, yavaş ilerleyici bir metabolik hastalıktır. Semptomların ortaya çıkış zamanına göre nöro-gelişimsel basamaklarda gecikme ve mental retardasyon hastalığın erken dönem bulguları olup, piramidal ve ekstrapiramidal bulgular ile serebellar bulgular sıklıkla yaşamın ilk iki dekadında ortaya çıkmaktadır. Hastalıkta, yaşamın ilerleyen dönemlerinde beyin neoplazmı gelişebilmektedir
(2). Yazımızda sunulan olguların ışığında, erken yaşta beyin tümörü saptanan hastalarda, eşlik eden gelişim basamaklarında gecikme, mental retardasyon ve patolojik muayene bulgularının varlığında metabolik hastalıkların da ayırıcı tanıda akılda tutulması, nöro-metabolik hastalıkların spesifik radyolojik bulgularının üzerinde durulması ve metabolik hastalıklarda aile taramasının önemi vurgulanmıştır.

Ortalama tanı yaşının 16,2 yaş (8-28 yaş) olduğu 16 L2HGA hastası ile yapılan bir çalışmada, en sık başvuru yakınması; yürümede bozulma, konuşma problemleri, epilepsi ve gelişimsel gecikme olarak belirtilmiştir. Verilerine ulaşılabilen hastaların tümünde nöbet gözlenmiş olup nöbetlerin başlama zamanı dört ay ile üç yaş arasında değişmektedir. Hastalardan dördünde beyin tümörü gelişmiştir (6).

Altmış bir L2HGA hastasının verilerine dayanan bir çalışmada ise tanı anında hastaların ortalama yaşı 2 yaş (0-7 yaş) bulunmuş, en sık görülen klinik bulgular gelişimsel gerilik, epilepsi, serebellar ataksi olarak sıralanmıştır. Hastaların bağımsız yürüme yetisini kazandığı ortalama yaş 1,8 $( \pm 0,9)$ 'dir (7).

L2HGA hastalarında beyin MRG bulguları hastalık açısından oldukça özgül olup farklı yakınmalarla yapılan görüntülemeler sonucunda hastaların tanı almasını sağlayabilmektedir. 17 L2HGA hastası ile yapılan bir çalışmada; hastalığın ortalama tanı yaşı 11,6 yaş (3-28 yaş) saptanmış, olguların tümünde fronto-temporal ak madde tutulumu izlenmiştir. Ak madde tutulumu olguların \%82,3'ünde subkortikal, $\% 11,72$ 'sinde santral, \%5,9'unda periventriküler yerleşimlidir. Tüm olgularda korpus kallozum ve serebellar ak madde korunmuştur. Sadece bir hastada beyin sapı tutulumu görülmüştür. Hastaların tümünde dentat nükleus tutulumu olup, altı hastada kaudat nükleus, 12 hastada putamen, 10 hastada globus pallidus ve üç hastada talamus tutulumu bildirilmiştir (8). Elli altı hasta ile yapılan başka bir çalışmada ise beyin MRG anormalliklerinin hastalığın süresi ile ilişkisi değerlendirilmiştir. Hastalığın progresyonu ile frontal subkortikal alandaki ak madde tutulumu global ak madde tutulumuna ilerlemiştir. Bazal gangliyon ve dentat nükleus tutulumu hastalığın erken döneminde de mevcutken globus pallidus tutulumu geçen süreden bağımsız bulunmuştur. İstatistiksel olarak serebral ve serebellar atrofi ile yaygın ak madde tutulumunun hastalığın süresi ile 
arasındaki ilişki anlamlı bulunmuştur (3). Hastalarımızın klinik ve nöroradyolojik bulguları literatür ile uyumluydu. Her iki olguda da gelişimsel gerilik ve mental retardasyon yaşamlarının erken döneminde başlamış olmasına karşın klinik tanı ancak birinci dekadın sonlarında konulabilmişti. Yazımızda, tanısal gecikmelerin önlenebilmesi amacıyla metabolik hastalıklarda beyin MRG görüntülemesinin yardımcı bir tanı yöntemi olarak kullanılabildiği ve patolojik nöroradyolojik bulguların tanısal ipucu olarak görev alabildiği vurgulandı.

L2HGA tanılı hastalarda beyin neoplazmı geliştiği bildirilmiştir. On bir hasta ile yapılan bir çalışmada yaşamlarının ikinci dekadında hastaların birinde gliom, birinde oligodendrogliom, birinde astrositom geliştiği bildirilmiştir. Aynı çalışmada, 295 hastayı kapsayan literatür verisi incelenmiş, 14 hastada neoplazm bildirilmiştir. Bu veriler eşliğinde L2HGA hastalarında ortalama beyin neoplazmı prevalansı \%5 saptanmış, neoplazm gelişme yaşı 3-6 yaş arasında dağılım göstermiştir. Yaş gruplarına göre neoplazmların patolojik tanıları farklılık göstermiştir. Yaşamın erken dönemlerinde medulloblastom, 9-12 yaş arasında düşük dereceli supratentoriyal kitleler, erişkin yaş döneminde ise düşük dereceli gliomların görülme sıklığı artmış olup, geç adolesan ya da erken erişkinlik döneminde yüksek dereceli gliom gelişimi bildirilmiştir (9). Hastamızda raporlanmış olan anaplastik ependimom, literatürde sık bildirilen ve L2HGA ile ilişkili olduğu gösterilen neoplazmlardan değildir.

Otozomal çekinik geçiş gösterdiği bilinen L2HGA için akraba evliliği önemli bir risk faktörüdür. Ülkemizde akraba evliliği oranı \%23,2 olup doğumsal metabolik hastalıkların görülme sıklığı yüksektir (10). Yazımızda indeks L2HGA vakası saptandıktan sonra aile taraması yapılarak tespit edilen bir vaka sunuldu. Geniş pedigri analizinde amcasında beyin tümörü varlığı öğrenildi ve L2HGA tanısının amca için de olası olduğu düşünüldü. Mevcut veriler ışığında, metabolik hastalık tanısı konulan hastaların aile taramasının yapılması ve soyağacının en az üç kuşağı kapsayacak şekilde çizilmesi gerektiği vurgulandı.

\section{Kaynaklar}

1. Van Schaftingen E, Rzem R, Veiga-da-Cunha M. L: -2-Hydroxyglutaric aciduria, a disorder of metabolite repair. J Inherit Metab Dis 2009; 32 (2): 135-42.

2. Hoffmann GF, Kölker S. Cerebral Organic Acid Disorders and Other Disorders of Lysine Catabolism. In: Saudubray JM, Baumgartner MR, Walter. J (eds). Inborn Metabolic Diseases Diagnosis and Treatment. 6th Edn. Berlin,Heidelberg: Springer; 2016: 333-48.

3. Steenweg ME, Salomons GS, Yapici Z, et al. L-2-Hydroxyglutaric aciduria: pattern of MR imaging abnormalities in 56 patients. Radiology 2009;251(3):856-65.

4. Yilmaz K. Riboflavin treatment in a case with I-2-hydroxyglutaric aciduria. Eur J Paediatr Neurol 2009;13(1):57-60.

5. Samuraki M, Komai K, Hasegawa $\mathrm{Y}$, et al. A successfully treated adult patient with L-2-hydroxyglutaric aciduria. Neurology 2008; 70 (13): 1051-2.

6. Faiyaz-UI-Haque M, Al-Sayed MD, Faqeih E, et al. Clinical, neuroimaging, and genetic features of L-2hydroxyglutaric aciduria in Arab kindreds. Ann Saudi Med. 2014;34(2):107-14.

7. Steenweg ME, Jakobs C, Errami A, et al. An overview of L-2-hydroxyglutarate dehydrogenase gene (L2HGDH) variants: a genotype-phenotype study. Hum Mutat. 2010;31(4):380-90.

8. Fourati $\mathrm{H}$, Ellouze $\mathrm{E}$, Ahmadi M, et al. MRI features in 17 patients with $\mathrm{I} 2$ hydroxyglutaric aciduria. Eur $\mathrm{J}$ Radiol Open 2016; 3: 245-50.

9. Patay Z, Mills JC, Löbel U, Lambert A, Sablauer A, Ellison DW. Cerebral neoplasms in L-2 hydroxyglutaric aciduria: 3 new cases and meta-analysis of literature data. AJNR Am J Neuroradiol 2012; 33 (5): 940-3.

10. Türkiye İstatistik Kurumu. Resmi internet sitesi: http://www.tuik.gov.tr 